\title{
EXPERIMENTAL EVALUATION OF THE IMPACT- ABSORPTION PROPERTIES OF RUBBER TILES FOR THE PLAYGROUND
}

\author{
Li-Tung Chang ${ }^{1}$, KUEN-HoRng TSAI $^{2}$, JIN-Shan ShiaU $^{1}$ \\ ${ }^{1}$ Department of Childhood Education and Nursery, \\ Chia Nan University of Pharmacy and Science \\ ${ }^{2}$ Department of Industrial Management, Southern Taiwan University of Technology \\ Taiwan
}

\begin{abstract}
Rubber tiles are popular in playgrounds as protective surfacing to reduce the incidence of head injuries caused by children falling from equipment. However, Taiwan has not yet established a test code for assessment of the shock-absorption properties of such surfacing. For this study, an experimental model was established to evaluate the behavior of various rubber tiles. A hemispherical headform was dropped from a set height to strike the center of the specimen tile. The peak acceleration and Head Injury Criterion (HIC) were measured to assess the impact absorption of and critical height for a given rubber tile. The results show that utilization of the HIC index provides a more conservative assessment of the shock absorption and, ultimately, protection from head injuries than peak acceleration. The maximum critical heights of the rubber tiles used in this study for tile thicknesses of 45, 60 and $80 \mathrm{~mm}$ were 1.6, 2.0 and $2.2 \mathrm{~m}$, respectively. Two-part rubber tiles with a base structure consisting of a box-like core offer superior protection from head injuries relative to analogous cylindrical, square pillar and solid structures. The maximum differences in peakacceleration and HIC values comparing the box-like core and solid structures at a thickness of 45 mm were $21 \%$ and $44 \%$, respectively. The results of this study suggest a minimum of rubber thickness of $60 \mathrm{~mm}$, based on probable maximum fall heights of more than $1.6 \mathrm{~m}$. Moreover, incorporation of an appropriate cushioning structure in the base of the rubber tile could further improve protection.
\end{abstract}

Biomed Eng Appl Basis Comm, 2004(October); 16: 244-250.

Keywords: head injury, playground safety, impact, standard

\section{INTRODUCTION}

Received: Mar 25, 2004; Accepted: Aug 30, 2004 Correspondence: Li-Tung Chang, Associate Professor Department of Childhood Education and Nursery, Chia Nan University of Pharmacy and Science, 60 Erh-Jen Road, Section 1, Jen Te, 717 Tainan, Taiwan

E-Mail: tchang@mail.chna.edu.tw
Playgrounds are a fundamental part of the childhood experience. As well as promoting physical development and the general idea of spatial relationships, playground activities foster acquisition of language, social skills, individual maturity and emotional control, and greatly improve general health. Equipment-related injuries are a serious problem, however, with falls the most common cause of accident [1-5]. We surveyed 1531 consecutive craniofacial injuries under 12 years of age children in Tainan, with falls accounting for the majority (57\%) [6]. The U.S. 
Consumer Product Safety Commission (CPSC) study revealed that $79 \%$ of equipment-related injuries involved playground falls [7]; specifically, $68 \%$ involved falls to the surface below the equipment. Of these, severe head injuries, which included fracture, concussion and internal-organ injury, have the potential for serious long-term consequences or even death, with approximately two-thirds of mortalities involving a head injury $[1-5,7]$. To safeguard against falls, protective surfacing around playground equipment is generally emphasized in developed countries to provide appropriate shock attenuation.

To determine the impact-absorbing properties of the protective surfacing around playground equipment necessary to prevent children's head injuries, standardized shock-attenuation tests [8-12] have been established in many countries. In these test procedures, a headform is used to strike the surfacing material, and the peak acceleration and Head Injury Criterion (HIC) [13] of the headform are evaluated. The critical height for a given surfacing is determined when the peak acceleration and HIC values for the headform are less than $200 \mathrm{G}\left(\mathrm{G}=9.8 \mathrm{~m} / \mathrm{s}^{2}\right)$ and 1000 , respectively. If children fall from below this critical height, then lifethreatening head injury would not be expected to occur. Hence, designers wishing to install protective surfacing around playground equipment should request the appropriate test data from the manufacturer, enabling them to design the installation so that the probable maximum fall height of children using the equipment does not exceed this critical value.

As Taiwan is a semi-tropical island, heat and humidity can increase maintenance costs. Therefore, rubber tiles, which are resistant to these factors, are widely used as protective surfacing. In general, these tiles are made from recycled tires, which have been milled into shreds (length: $5 \sim 15 \mathrm{~mm}$, width: $1 \sim 5 \mathrm{~mm}$ ), and then mixed with resin to make the rubber tile in a hot-press molding process. The tiles typically comes in several thicknesses $(15,25,45,60,80$ and $100 \mathrm{~mm})$, making them suitable for a variety of applications. However, most of the rubber tiles used in Taiwanese playgrounds are only $25 \mathrm{~mm}$ in thickness, with the 45 $\mathrm{mm}$ analogs less prevalent and thicker tiles not common. It seems reasonable to suggest that the most important factor dictating this unsound practice is that a standardized shock-attenuation code has not been established for Taiwan and, therefore, there is no suitable information relating to the impact-absorbing capability of different rubber tiles to provide playground designers and managers with the guidelines necessary for installation of safe protective surfacing.

Thicker rubber tiles (over $45 \mathrm{~mm}$ ) generally consist of surface and base layers. A solid, planar surface $(20 \mathrm{~mm})$ on top of base layers while base layer has various structures, including box-like core, pillar and solid forms. The structure of the base layer affects dynamic response during child head impact, however, few studies have assessed the ability of the two-layer tile to protect against head injury, and the effect on the impact-absorption capability of the base structure is seemingly unclear.

The objectives of this research were, therefore, to establish an experimental model for assessment of the impact-absorbing capability of playground surfacing materials, and to evaluate the protective performance of rubber tiles with respect to the probability of head injuries at distinct thicknesses and for various basestructure designs.

\section{MATERIALS AND METHODS}

\subsection{Shock Absorbing Test}

To evaluate the impact absorption of the rubber tiles, experimental devices were set up according to the procedures for the ASTM systems [10-11] (Fig. 1). A three-axial accelerometer (356A02; PCB Piezotronics Inc., USA) was installed at the center of a $4.6-\mathrm{kg}$ magnesium-alloy headform, a hemispherical impactor of diameter $160 \mathrm{~mm}$, with its $z$ axis aligned with the direction of gravity. The headform was dropped without guidance to the base of the device on the floor. During impact, the acceleration of the headform was recorded using the accelerometer output and a dataacquisition device (DAQCard-6062E; National Instruments, USA) connected to a computer and display. The trial height for the impact tests was incremented by $30 \mathrm{~mm}(1,2,3 \ldots \mathrm{n})$ until a maximum acceleration not exceeding $300 \mathrm{~g}$ was achieved. For each height, the impact test consisted of three drops onto the same impact site, with the averages of the evaluated indexes of second and third drops calculated to represent the impact-absorbing capability.

\subsection{Specimens}

The test specimens consisted of four types of rubber tile (Table 1), with uniform dimensions of 500 $\times 500 \mathrm{~mm}$, and thicknesses of $15,25,45,60$ and 80 $\mathrm{mm}$. To evaluate the effect of the structure of the rubber tile, each specimen consisted of surface and base layers, except for the specimens with thicknesses of 15 and $25 \mathrm{~mm}$. The $20-\mathrm{mm}$ surface layer was solid, with different base layers: solid (A), square pillar (B), cylinder (C), and box-like core (D) (Fig. 2).

\subsection{The Evaluation Indexes}

To determine the critical height of each rubber tile, the peak acceleration of the headform during the 
impact was set at $200 \mathrm{G}$ as the reference value [8-12]. The HIC was calculated to evaluate potential brain injuries; with the tolerance level specified at 1,000 [812,14-16]. Calculation of the HIC involves not only consideration of the peak acceleration but also the distribution and duration of the acceleration over the time of impact. This criterion is the maximum value obtained from the equation:

$$
H I C=\left[\frac{1}{t_{2}-t_{1}} \int_{t !}^{t^{2}} a(t) d t\right]^{2.5} \cdot\left(t_{2}-t_{1}\right)
$$

and calculated from a plot of acceleration, $a(t)$ (in $G$ ) against time, $t$ (in seconds), where $t_{1}$ and $t_{2}$ are the bounds of all possible time intervals throughout impact.

\section{RESULTS}

\subsection{Thickness}

Comparison among different thickness tiles revealed different trends for the two evaluated indexes. The plot of peak acceleration and drop-height was essentially linear (Fig. 3), with roughly three-order polynomial fitting demonstrated for the HIC and dropheight plot (Fig. 4). The slopes of the plots for both indexes decreased as the thickness of the tile specimen was increased from 15 to $80 \mathrm{~mm}$. In general, HIC was more conservative for evaluation of the critical height of the rubber tile than peak acceleration. Of the tested specimens, the plot for type $C$ specimen tiles had the lowest slope (i.e., it had the best protective performance). Peak acceleration for the $15-\mathrm{mm}$ specimen had over $300 \mathrm{G}$ at $0.6 \mathrm{~m}$, with the $25-\mathrm{mm}$ analog exceeding the tolerance level $(200 \mathrm{G})$ at $0.9 \mathrm{~m}$. The critical heights for the 45,60 and $80-\mathrm{mm}$ specimens were 1.9, 2.7 and $>3 \mathrm{~m}$, respectively (Fig. 3 ). The HIC values for the 15 and $25-\mathrm{mm}$ specimens exceeded $\mathrm{HIC}$ tolerance $(1000)$ at 0.5 and $0.9 \mathrm{~m}$,

Table 1 Rubber-tile types and fundamental parameters

\begin{tabular}{lcccc}
\hline Type & $\begin{array}{c}\text { Density } \\
\left(\mathrm{kg} / \mathrm{m}^{3}\right)\end{array}$ & $\begin{array}{c}\text { Base layer } \\
\text { structure }\end{array}$ & $\begin{array}{c}\text { Cross-section } \\
\text { dimension } \\
(\mathrm{mm})\end{array}$ & $\begin{array}{c}\text { No. of } \\
\text { specimens }\end{array}$ \\
\hline $\mathrm{A}$ & 736 & solid & --- & 16 \\
$\mathrm{~B}$ & 753 & square pillar & $50 \times 50$ & 16 \\
$\mathrm{C}$ & 755 & cylinder & $\psi=60$ & 16 \\
$\mathrm{D}$ & 726 & box-like core & $35 / 15^{*}$ & 20 \\
\hline$\psi=60:$ diameter of cylinder & &
\end{tabular}

*35/15: square hollow of $35 \times 35 \mathrm{~mm}$, the plate thickness of $15 \mathrm{~mm}$ respectively. The critical heights for the 45,60 and 80 mm specimens were $1.6,2.0$ and $2.2 \mathrm{~m}$, respectively (Fig. 4).

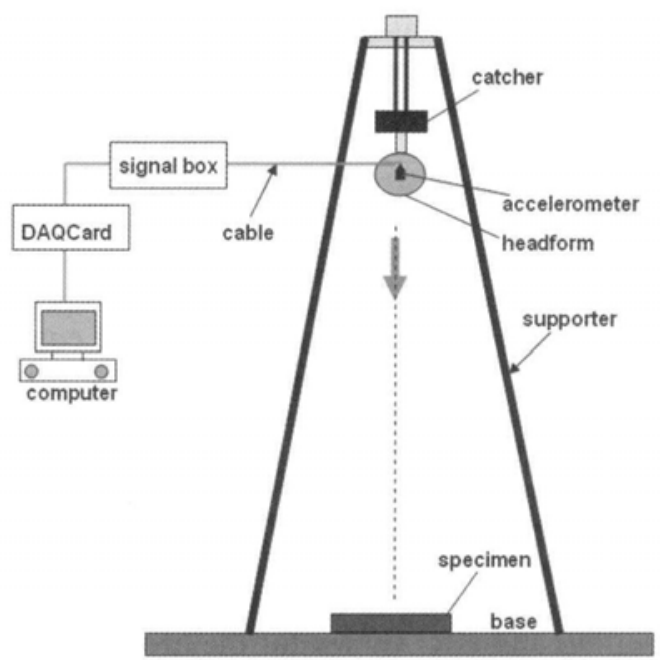

Fig 1. Experimental setup for shock absorption testing of rubber tile.

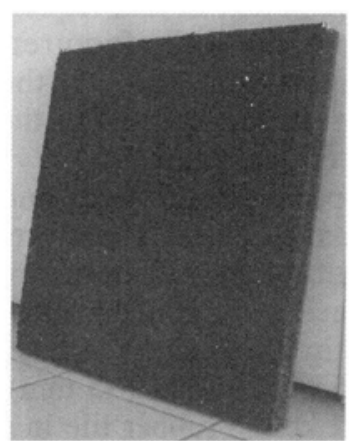

(a)

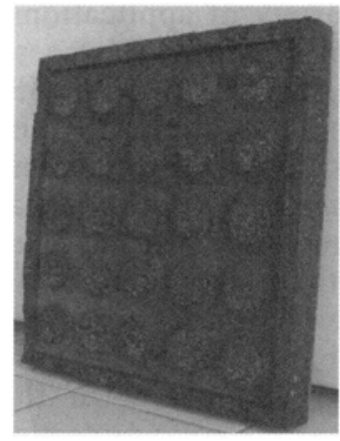

(c)

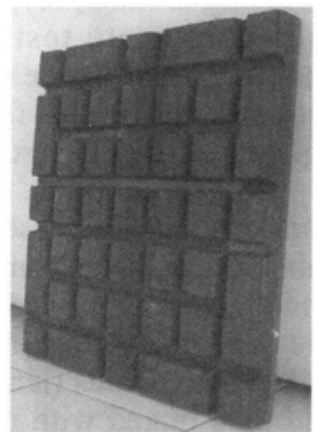

(b)

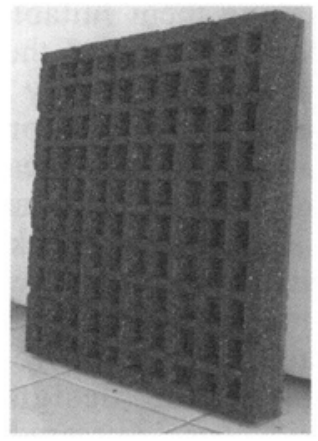

(d)
Fig 2. Four base-layer structures: (a) solid; (b) square pillar; (c) cylinder; and, (d) box-like core. 


\subsection{Base Structure}

Comparing the peak acceleration and HIC values for different base structures revealed the same order of protective performance. The best impact-absorbing capacity was demonstrated for box-like core, followed by the cylinder, square pillar, and solid variants, in descending order of performance. As can be seen from Figures 5 and 6 , the differences between the four base structures in terms of both index values increased as drop height increased. At $2.1 \mathrm{~m}$, the maximum variations in peak acceleration and $\mathrm{HIC}$ values for the 45 -mm items were $21 \%$ and $44 \%$, respectively.

\section{DISCUSSION}

The peak acceleration dictates the maximum force on the head during impact. When the maximum force is increased, the incidence of head injury rises. Further, the Wayne State University cerebral tolerance curve (WSTC) reflects the relationship between incidence of head injury and distribution and duration of the force during impact [17], and then, the Head Injury Criterion was proposed by Versace [13] to describe the tolerance curve to facilitate assessment of the incidence probability of head injury. The specific aim of this study was to evaluate and discuss the protective performance of rubber tiles of different thicknesses and structure designs in the context of playground head injury in children. Neurological and soft-tissue sequelae were considered beyond the scope of the investigation, however, which focused only on utilization of engineering indexes, peak accelerations and HIC for evaluation of the relative probability and

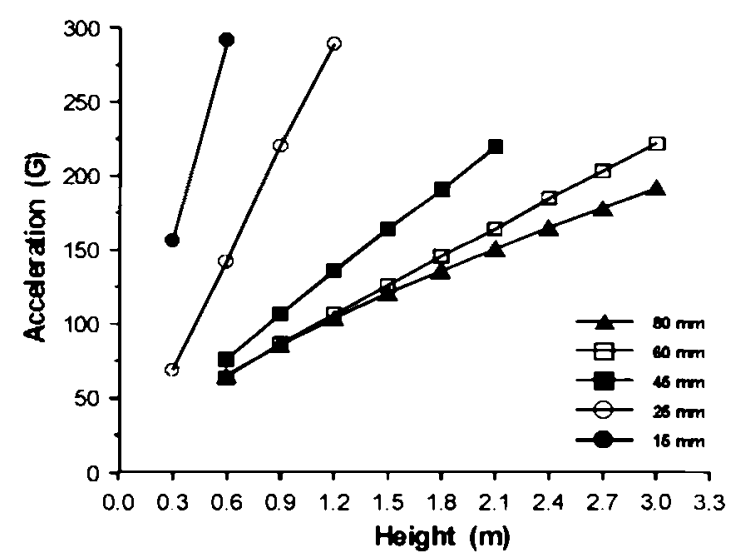

Fig 3. For type $\mathrm{C}$ specimens, the peak accelerations for the 45,60 and $80-\mathrm{mm}$ variants exceeded tolerance level $(200 \mathrm{G})$ at $1.9,2.7$ and $>3 \mathrm{~m}$, respectively.

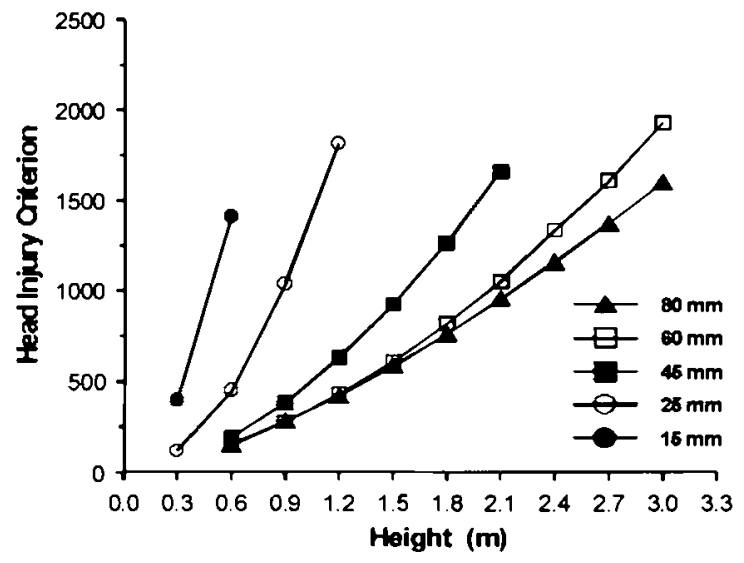

Fig 4. For type $C$ specimens, the HIC values for 45 , 60 and $80-\mathrm{mm}$ rubber tile exceeded the tolerance level (1000) at 1.6, 2.0 and $2.2 \mathrm{~m}$, respectively.

comparative severity of any resultant head injuries.

Of the two indexes, the plot of HIC and drop height approached a three-order polynomial fitting (Fig. 4), however, the curve for peak acceleration and drop height reflected a roughly linear relationship (Fig. 3 ). Utilization of the HIC index appears to impose more conservative requirements on the protective performance of tiles than peak acceleration value. This is because the former depends on both the peak acceleration and the distribution of the accelerationtime trace, making it more sensitive to variation than peak acceleration in terms of assessment of the critical height of a given type of rubber tile in terms of prevention of head injury.

In many countries, there are no limits to probable maximum fall height for playground equipment $[8,12]$, while in others it is $2.5 \mathrm{~m}$ [18]. The CPSC [7] has rescarched playground equipment-related injuries, revealing that $78 \%$ of all falls to the surface occurred from heights of $1.8 \mathrm{~m}$ or less, however, the other $22 \%$ were between 1.8 and $3 \mathrm{~m}$. In Taiwan, according to our observations, most probable maximum fall heights for playground equipment for preschool-age children (under 6 years of age), are $1.8 \mathrm{~m}$ or less. For schoolage children, however, most of the analogous equipment, especially climbers and slides, has fall heights in excess of that figure. However, the thickness of the rubber tiles surrounding the equipment is almost less than $45 \mathrm{~mm}$, with most playground surfacing 25 $\mathrm{mm}$ in thickness. In this study, it was demonstrated that type $\mathrm{C}$ tiles, with base structure of box-like core, had the best protective performance in terms of prevention of head injury, however, critical heights for the 25 and $45-\mathrm{mm}$ tiles was only 0.9 and $1.6 \mathrm{~m}$, respectively. These results indicate that the impact-absorbing capacity of the rubber surfacing under most of the 
playground equipment in Taiwan is inadequate in terms of protection from head injury in children.

The thickness and composition of a child's skull offers less protection in comparison to that of the adult. Skull stiffness is a non-linear function of age, attaining $75 \%$ of the adult value from six-to-nine years, $60 \%$ at three years, and $30 \%$ at 12 months [19]. Hence, the U.S. Federal Motor Vehicle Safety Standard [20] stipulates HIC limits for 12-month, three and six-yearold children of 390,570 and 700 , respectively. This implies that the present HIC criterion of 1000 for protective surfacing in playgrounds is inadequate, and that surfacing materials, which meet this criterion may not necessarily be able to prevent head injuries from a fall impact. When the tolerance level was set at 700 , critical heights for type $C$ specimens with 60 and $80-$ $\mathrm{mm}$ thickness were only 1.6 and $1.8 \mathrm{~m}$. Additionally, rubber deterioration resulting from the effects of temperature and exposure to sunlight must be taken into consideration outdoors [21-23]. The rubber tiles gradually lose their compliance when exposed to the elements, so that the impact absorption of the tiles is decreased as the utilization time increases. The findings above suggest that for playground equipment where the highest designated play surface exceeds 1.6 $m$, the thickness of rubber tiles under and around the equipment should be at least $60 \mathrm{~mm}$ to prevent head injuries in children.

Of the different tile structures, the non-solid base layer had superior impact absorption in comparison to the solid variant (Fig. 5 and 6). At a drop height of 2.1 $\mathrm{m}$, the maximum variations in peak acceleration and HIC values comparing the tiles with box-like core and solid structure at a thickness of $45 \mathrm{~mm}$ were $21 \%$ and $44 \%$, respectively. The reason for this was that the non-solid layer provided a cushioning structure and thus absorbed more impact energy. This effect is

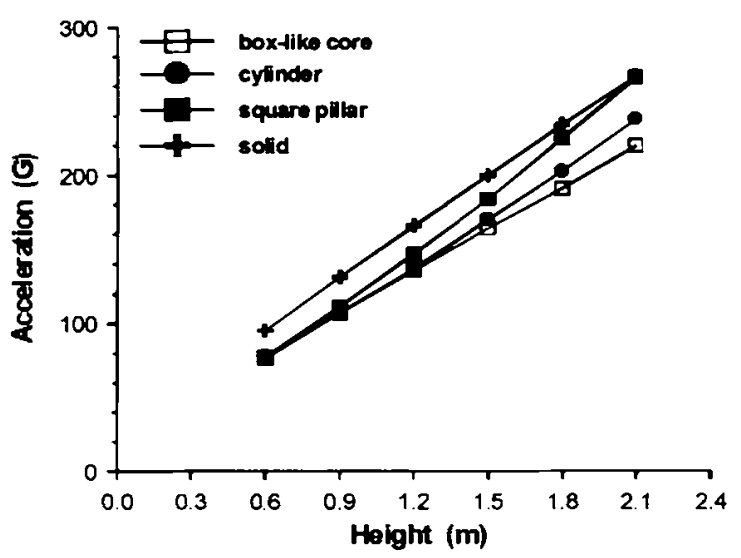

Fig 5. The peak accelerations for the four base structures at an overall thickness of $45 \mathrm{~mm}$. apparent when reviewing the acceleration-time traces of the headform during impact (Fig. 7). The traces for the non-solid layer were skewed to the right during the loading path and peak acceleration was reduced. Furthermore, the box-like core had superior impactabsorbing capability in comparison to the cylinder and square-pillar variants. This was because the box-like core of the tile used in this study was of plate-cell construction (Fig. 2d), with the plate much thinner in the transverse direction and lower shearing stiffness in comparison to the cylinder and square pillar (Fig. 2b and $c$ ). When the headform struck the surface of this specimen in normal direction, the deformation of the plate produced by the transverse shear was much greater than in the cylinder and square-pillar variants. This effect increased the energy absorption of the tile during impact and reduced the critical load, beginning to bending deformation of the plate in transverse

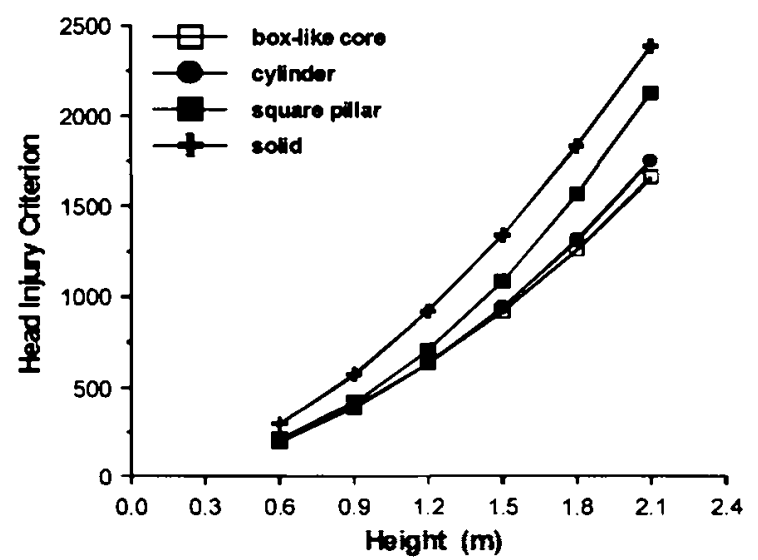

Fig 6. HIC values for the four base structures at an overall thickness of $\mathbf{4 5} \mathbf{~ m m}$.

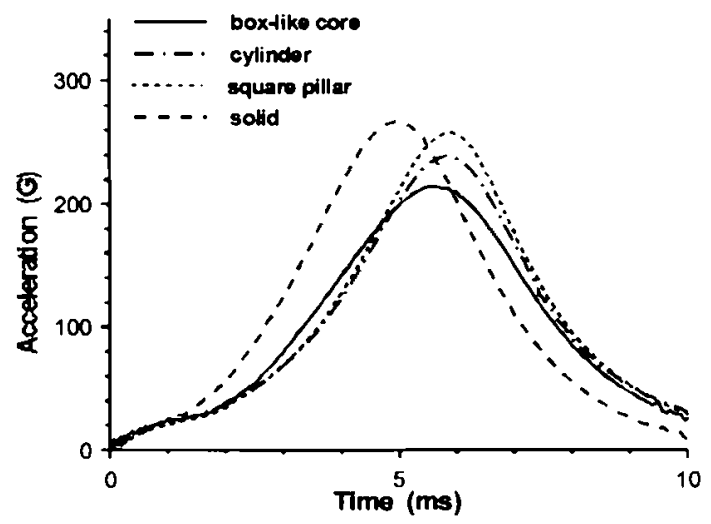

Fig 7. Acceleration-time curves for the headform using different base structures $(45 \mathrm{~mm})$ at a drop height of $2.1 \mathrm{~m}$. 
direction, hence, reducing the peak acceleration of the headform. This observation suggests that a design that incorporated appropriate cushioning structure in the base layer of the rubber tile would enhance its impactabsorbing capability.

\section{CONCLUSIONS}

Establishing a procedure to test the protective surfacing around playground equipment will help local communities, schools, kindergarten, corporations, and other groups build safer playgrounds for children in Taiwan. The surfacing material used under and around any given piece of playground equipment should have a critical-height value equivalent to or greater than the highest designated play surface.

The HIC is more conservative than peak acceleration for estimation of the critical height for rubber-tile installations and, ultimately, prevention of head injury in children. In this study, the impact absorption of rubber tiles of $45-\mathrm{mm}$ thickness or less was insufficient where fall heights were over $1.6 \mathrm{~m}$. On the basis of these experimental results, therefore, we suggest a tilc thickness of at least $60 \mathrm{~mm}$ for playgrounds in Taiwan as the probable maximum fall heights are over $1.6 \mathrm{~m}$. Moreover, in order to improve the energy-absorbing capability of rubber tile, the cushioning effect of the base layer should be maximized by selection of the most-effective design. Based on our analysis, it seems reasonable to suggest that a core design incorporating plate-cell construction increases encrgy absorption and reduces critical load, offering superior impact protection.

\section{ACKNOWLEDGEMENTS}

This study was supported by a great from the National Science Council of the Republic of China (Grant No. NSC-91-2213-E-041-001 and 90-2213-E041-004). We appreciate to Miss Ho Hsiu-Ting and Cheng Ju-Chun of Department of Childhood Education and Nursery, Chia Nan University of Pharmacy and Science, for help in shock absorption performance test.

\section{REFERENCES}

1. Gallagher SS, Finison $K$, Guyer $B$ and Goodenough: The incidence of injuries among 87000 Massachusetts children and adolescents: results of the 1980-81 statewide childhood injury prevention program surveillance system. American Journal of Public Health, 1984; 74:1340-1347.

2. Kraus J F, Fife D, Cox P, Ramstein K and Conroy $\mathrm{C}$ : Incidence, severity, and external causes. American Journal Diseases of Children 1986; 140 : 687-693.

3. Alwash R and McCarthy M: Measuring severity of injuries to children from home accidents. Archives of Disease in Childhood 1988; 63: 635-638.

4. Anderson P J: Fractures of the facial skeleton in children. Injury 1995; 26: 47-50.

5. Reece RM and Sege R: Childhood head injuries: accidental or inflicted? Archives of Pediatrics and Adolescent Medicine 2000; 154: 11-15.

6. Chang LT, Tsai MC, Lin JR and Liu DS: The study of head injury prevention of children on playground equipments. Proceedings of Biomedical Engineering Society 2003 Annual Symposium, Taipei, Taiwan, 2003.

7. Tinsworth DK and McDonald JE: Injuries and deaths associated with children's playground equipment. U.S. Consumer Product Safety Commission, Washington, 2001.

8. CPSC \#325: Handbook for public playground safety. U.S. Consumer Product Safety Commission, Washington 2003.

9. CPSC \#1005: Playground surfacing materials. U.S. Consumer Product Safety Commission, Washington 2003.

10. F 1292: Standard specification for impact attenuation of surface systems under around playground equipment. American Society for Testing and Materials, Pennsylvania, USA, 1999.

11. F 355: Standard Test Method for Shock Absorbing Properties of Playing Surface Systems and Material. American Society for Testing and Materials, Pennsylvania, USA, 1986.

12. EN 1177: Impact absorbing playground surfacing safety requirement and test methods. CEN, 2000.

13. Versace J: A review of the severity index. Proceedings of 15 th Stapp Car Crash Conference, New York, 1971.

14. Chang LT, Chang $\mathrm{CH}$ and Chang GL: Experimental evaluation of chin bar on head injury in facial impact. JSME International Journal, Series A, $1998 ; 42:$ 294-300. 
15. Chang $\mathrm{CH}$, Chang LT, Chang GL, Huang SC and Wang $\mathrm{CH}$ : Head injury in facial impact ?a finite element analysis of helmet chin bar performance. ASME: Journal of Biomechanical Engineering, 2000; 122: 640-646.

16. Collants M: Evaluation of the importance of using head injury criterion (HIC) to estimate the likelihood of head impact injury as a result of a fall onto playground surface materials, U.S. Consumer Product Safety Commission, Washington, 1990.

17. Gurdjian ES, Hodgson VR, Hardy WG, Patrick LM and Lissner HR: Evaluation of the protective characteristics of helmets in sports. Journal of Trauma 1964; 4: 309-324.

18. CNS 12642: Safety aspects of playground equipment - design and installation, Chinese National Standard Institution, Taipei, Taiwan, 1991.
19. Yoganandan N, Kumaresan S, Pintar FA and Gennarelli TA: Biomechanical tolerance criteria for paediatric populations. Proceedings, Child Occupant Protection in Motor Vehicle Crashes, Professional Engineering Publishing Limited, London, 1999; 97-112.

20. FMVSS DOT 208: Occupant crash protection, Federal Motor Vehicle Safety Standard, U.S. Department of Transportation, Washington, 1999.

21. D518: Standard Test Method for Rubber Deterioration -- Surface Cracking, American Society for Testing and Materials, Pennsylvania, USA, 1999.

22. D1148: Standard test method for rubber deterioration-heat and ultraviolet light discoloration of light-colored surfaces, American Society for Testing and Materials, Pennsylvania, USA, 2001.

23. D572: Standard test method for rubberdeterioration by Heat and Oxygen, American Society for Testing and Materials, Pennsylvania, USA, 1999. 